\title{
Research on Government Engineering Procurement Evaluation System Yin Dechun
}

\author{
China CNTC international tendering corporation, Beijing, China \\ yindechuncntc@sina.com
}

\section{Keywords: Government Engineering, Procurement, Evaluation System}

\begin{abstract}
In China, the government procurement system is taking shape, and entered into legal management stage. Among them, the proportion of government procurement project procurement accounts for the total size of the increase year by year, will become more and more important role. In the government procurement process engineering, evaluation as an important part of the Government Engineering Procurement tender directly affect the quality and credibility of government procurement. However, our existing evaluation system, there is a certain lack of scientific and reasonable terms. This article is in this context, the evaluation system for government procurement projects carried out in-depth research.
\end{abstract}

\section{Introduction}

Government procurement has 200 years of history in the world and in our country, government procurement is an important part of the reform of financial expenditure, the government procurement system is taking shape, and entered into legal management stage. The fourth quarter of 2008 to 2010 to add 4 trillion investments in expanding domestic demand, the new public investment 1.18 trillion $\mathrm{RMB}$. In our government procurement, engineering, procurement accounting for the total size of the proportion of government procurement increased year by year. Therefore, the Government Engineering Procurement in government procurement in our increasingly important role.

Evaluation directly affects the quality and credibility of government procurement. Evaluation and Determination of evaluation criteria is an objective measure of scale, scientific and rational evaluation of their behavior directly affects the evaluation experts and the results of evaluation of impartiality. And our existing evaluation system, there is a certain lack of scientific and reasonable terms. For example, the evaluation index system is unreasonable, because the complexity of the project, types, effects of different size, long period, so in the index set, easy to miss some of the influencing factors, particularly with respect to public procurement, not only to the economic as well as technical and comprehensive benefits society; index system weighting coefficient set unreasonable, experts consider only qualitative projects each index weight coefficient, the lack of effective government project bid decision-making mechanisms; lack of scientific evaluation mode named in the technical, economic and social comprehensive optimum effectiveness of good standard.

\section{Research on Government Engineering Procurement Evaluation}

Government procurement projects, the Government refers to co-ordinate the country's financial capital construction, reconstruction, expansion behavior and its annex building and social transformation of the natural environment. Government Engineering Procurement projects may include three categories: (1) large-scale infrastructure, including the relationship between the public interest and public safety utility projects; (2) an international organization or foreign government loan assistance projects; (3) to set up the auspices of the State or financing of the project.

Government procurement project bid evaluation group evaluation refers to the evaluation committee or government procurement center project organization commissioned by the purchaser, after opening the bidding process in accordance with the specific provisions of the tender documents and bidding requirements for qualified bidders to prepare and submit document the entire process of comparison, review and review. Wherein for major projects before the government procurement 
center project organization opening, construction project bidding Management Office should send site supervision, site supervision units involved include notary, auditing, supervision, finance.

Government Engineering Procurement needs to develop specific evaluation methods, which can improve the operability. Evaluation methods must be fair and impartial and shall not have the terms of any hint of discrimination; comprehensive evaluation methods should be noted that, taking into account both the common and taking into account the personality; in order to accurately determine the difference between the tender documents, evaluation methods should be scientifically sound; evaluation methods should have a strong operational, straightaway, without losing accuracy due. The basic problem in the evaluation of the tender documents in tender notes have been some explanation, but it is generally more rough, poor practice, or operate large stretch, therefore, to develop a reasonable and orderly evaluation methods is absolutely necessary . After completion of the evaluation methods developed need to submit the relevant government project procurement management agency review finds.

\section{The Problems in Government Engineering Procurement Evaluation System}

Government project procurement evaluation method needs to be improved. Government procurement projects in the bidding process, the pre-control target primarily frugal government spending, has now transformed into systematic consideration of the subject matter of the procurement and service quality products, so the current evaluation method can not only care about the price, it should be systematically many factors to consider technical, economic, management, social and other reasonable scientific evaluation methods, selected advanced technology, reasonable prices, scientific management, good reputation of the bidders, so as to prevent negative phenomena occurring in the bidding process, to achieve trick bid-win.

Scientific Rationality Functional Evaluation System government procurement projects to be improved. Seen from the current evaluation practices in government procurement projects, government departments around according to their actual conditions, set the evaluation index system of different forms, however, a variety of problems do exist, such as a simple indicator system, single-level, difficult to grasp the expert appraisal standards and other issues, leading to the evaluation results are unfair. Therefore, the evaluation index system of government procurement projects should be more efforts from the scientific rationality index system.

The preparation of tender documents by the expertise of staff limitations, determine the bidding documents evaluation methods and standards are not detailed, bidders cannot comprehend information and specific evaluation criteria of government procurement object. When high-tech preparation of tender documents, the general can only express the technical specifications, evaluation criteria difficult to develop, and limited technical expert advice is restricted by confidentiality clauses of the judges. Tender documents the evaluation criteria to determine the lack of scientific basis, to bring some difficulties to evaluation work.

\section{The Establishment Principles of the Government Procurement Evaluation System}

In accordance with the principles and requirements of scientific research in empirical and normative unity, establish a government procurement bid evaluation indicator database, there are two general guiding principles, one scientific, the second is practical. Scientific principle requires, the indicators designed to reflect the objectives and characteristics of government procurement, reflecting the government procurement function, the exact concept, meaning clear, clear calculation range, the system can be fully and objectively evaluate the strength of enterprises and their products Tender status. Practicality principle requires, the index system should be designed to more accurately evaluate the strength of enterprises and their products Tender status, easy to operate. In order to meet the requirements of these two guiding principles in the process of establishing a comprehensive evaluation index system of government procurement, the following specific principles should be followed: 
Comprehensive systematic principle. First, a comprehensive evaluation index system should fully reflect the actual situation the Government Procurement Evaluation objects that fully reflect the consolidation of the overall strength of the bidders and their products. Second, government procurement evaluation involves social, economic and technical efficiency evaluation index set should therefore take full account of the contents of these three areas.

The comparability principle. When analyzed using the evaluation system, we should use vertical, horizontal comparative analysis, in order to make the evaluation results more meaningful to consider the caliber index, calculated in regional, international and mutual consistency and comparability of history.

The qualitative and quantitative principles. Analysis of quantitative indicators main emphasis on comprehensive and reflects a lack of relevance. If only quantitative indicators, objective and comprehensive evaluation is difficult to achieve, and sometimes it may also appear large deviation. Therefore, give full play to the role of evaluation experts, the credibility of some of the variables, and service to be described by qualitative indicators such as, in the evaluation of the analysis, and then the quantification of qualitative indicators to be reflected approximations to achieve qualitative and quantitative combination.

The hierarchy principle. Government procurement evaluation factors involved are many and complex, to accurately and comprehensively reflect the bidding company and its products, the evaluation system should exhibit a hierarchical structure. Were evaluated at different levels can not only get the total evaluation results, but also to understand the various levels of evaluation status.

\section{The Establishment of Government Procurement Evaluation System}

According to the technical economic index system of ways to build audiences and government procurement government procurement bid evaluation indicator database must first clear the bid evaluation; Second, the system analysis and evaluation of government procurement target objects, choose a comprehensive evaluation criteria; again Select evaluation criteria to reflect these indicators, then index segment, index descriptions as needed; and finally, by some indicators seek expert advice, or the use of certain data processing techniques.

Select aspects of a comprehensive evaluation criteria, since the establishment of the government procurement bid evaluation indicator database is a huge project, so select the evaluation criteria cannot be based only on the subject of evaluation and analysis of government procurement objectives, but also drew extensively at home and abroad tender evaluation experience, and experience of non-commercial procurement tender vendor evaluation. Taking these aspects, I believe that government procurement more complete evaluation indicator database from the following nine aspects of the assessment that the financial situation, production capacity and equipment status, human resources, quality system and product quality status, performance, the tender price, service conditions, environmental protection measures, level of enterprise information.

After determining evaluation criteria, select indicators that can reflect the nine guidelines, which can be broken down and indicators broken down, the initial formation of the evaluation index system.

\section{Improvement of Government Engineering Procurement Evaluation Index System Design}

Government procurement bidding project evaluation is the whole process is the most important part. Many people choose a bid investment, short construction period, excellent quality of construction enterprises, and whether the bidder will win the fierce competition in the market, we need to determine through scientific and rational evaluation, and evaluation work is the most important basis for evaluation indicators. Evaluation metrics to consider bidding for construction projects to determine the contents. Design evaluation index system on the basis of the above classification evaluation indicators, the indicators by refinement and comprehensive sub gradually devised indicators. 
Screen index. Screening index is mainly used in the prequalification stage, mainly on the qualification of applicant and this article is mainly used for government projects eligible for public procurement tender prequalification. Qualification tender applicants are mainly from the relevant circumstances historical performance, financial condition of, the Commonwealth of between three aspects of the assessment.

Sort index. Sort detailed indicators used in the evaluation stage, which reviewed the optimal tender applicants. Sort indicators of decomposition subdivided into three main factors: economic factors, technological and social factors. The so-called economic factor evaluation refers to the evaluation of economic efficiency of government procurement projects, mainly from the price, quality engineering evaluation of the extent of government procurement projects to meet demand. Construction design is one of the key factors in the evaluation of construction projects. Construction design engineering construction projects and strategic guidance document is the outcome of the design intent and design into the overall plan to achieve, have a decisive impact on the technical and economic effects of the construction project. Here the so-called social evaluation mainly refers to the various protection measures advocated by the government, including environmental protection, industry support and protect the vulnerable situation.

Reference index. Reference indicators, including risk of default and claims experience. Risk indicators risk refers to the possibility of public works procurement process due to a long period, resulting in a huge investment, including the risks and risk procurement market risk, technology generated in the course of business generated. Feasibility studying the bidder technology risk generated by the use of technology, safety; risk Procurement market risks arising in the study materials market procurement process; risk management process produced mainly on the bidder's management capacity, the project social benefits. Claims of breach of contract claim expressed in the case of default occur during the time of performance of the contract.

\section{Conclusion}

As the Government Procurement our late start, limited by various conditions, China's government procurement evaluation work is still there are some problems, evaluation work is not standardized operation and evaluation criteria of irregularities and imperfections are directly linked. Therefore establish a scientific, unified government procurement evaluation index system can standardize the evaluation criteria, the evaluation work to solve the non-standard issues of importance.

\section{References}

[1] B. N. Ma, The state government procurement management system, J. Chinese Financial Information. 44 (2010) 146-147.

[2] H.X.Zeng, The dilemma faced by China's government procurement and countermeasures, J. Trade Finance. 18(2005) 55-57.

[3] J.H.Xue, Establishing government procurement system initial ideas, J. Coastal Economy, 32(2012) 189-190.

[4] Y.J.Qi, Government procurement system: international experience and reference, J, China Reform, 4(2007) 38-40.

[5] Y.M.Tian, International comparison of government procurement system and implications for China, J. Theorists, 9(2013) 142-150. 